\title{
Convergência dos Planos de Ensino ao Projeto Político Pedagógico, quanto às metodologias de ensino
}

\author{
Convergence of Teaching Plans to the Pedagogical Political Project as to teaching methodologies \\ Convergencia de Planes Didácticos al Proyecto Político Pedagógico en metodologías didácticas
}

Recebido: 23/10/2021 | Revisado: 04/11/2021 | Aceito: 10/11/2021 | Publicado: 14/11/2021

Simone da Silva Conceição

ORCID: https://orcid.org/0000-001-8454-1944 Universidade Federal do Rio Grande do Sul, Brasil

E-mail:conceicao.simone@yahoo.com.br

Leila Chaves Cunha

ORCID: https://orcid.org/0000-0002-8496-7985 Serviço Nacional de Aprendizagem Comercial, Brasil

E-mail: leilacunha1510@gmail.com

Edson Luiz Lindner

ORCID: https://orcid.org/0000-0002-6698-7085 Universidade Federal do Rio Grande do Sul, Brasil

E-mail: edson.lindner@ufrgs.br

\begin{abstract}
Resumo
O objetivo do presente artigo é identificar a convergência dos planos de ensino, do $5^{\circ}$ ano do Ensino Fundamental, ao Projeto Político Pedagógico (PPP), em relação às metodologias de ensino, de uma escola do estado de Santa Catarina. Trata-se de pesquisa descritiva, de cunho qualitativo. Para o tratamento dos dados aplica-se a técnica de análise de conteúdo proposta por Bardin (1977). Os resultados demonstram que, de forma geral, os procedimentos metodológicos previstos nos planos de ensino convergem com os identificados no PPP da escola, embora que alguns professores não apresentam procedimentos convergentes com o PPP. Conclui-se que os professores apenas elencam os procedimentos, sem esclarecer, de forma mais detalhada, como os procedimentos metodológicos serão desenvolvidos.
\end{abstract}

Palavras-chave: Plano de ensino; Projeto Político Pedagógico; Metodologias de ensino; Ensino fundamental.

\begin{abstract}
The present study aims at identifying the existing convergence between the 5th-grade Elementary School teaching plans and the Political Pedagogical Project (PPP) related to the teaching methodologies running in a private school at Santa Catarina State. This is a descriptive qualitative research. For data processing, researchers applied the content analysis technique proposed by Bardin (1977). The results showed that, in general, the methodological procedures presented in the teaching plans converged with those established in the Political Pedagogical Project, despite some gaps from some projects not aligned with the school PPP. Evidence showed that some teachers only listed the procedures without clarifying the teaching methods applied.
\end{abstract}

Keywords: Teaching plan; Pedagogical Political Project; Teaching methodologies; Elementary school.

\section{Resumen}

El objetivo de este artículo es identificar la convergencia de los planes de enseñanza, desde el $5^{\circ}$ año de la escuela primaria, al Proyecto Político Pedagógico (PPP), en relación a las metodologías de enseñanza, en una escuela del estado de Santa Catarina. Se trata de una investigación descriptiva y cualitativa. Para el procesamiento de datos se aplica la técnica de análisis de contenido propuesta por Bardin (1977). Los resultados muestran que, en general, los procedimientos metodológicos previstos en los planes docentes convergen con los identificados en el PPP de la escuela, aunque algunos docentes no presentan procedimientos que converjan con el PPP. Se concluye que los docentes solo enumeran los procedimientos, sin aclarar, con más detalle, cómo se desarrollarán los procedimientos metodológicos.

Palabras clave: Plan docente; Proyecto Político Pedagógico; Metodologías de enseñanza; Escuela primaria. 


\section{Introdução}

A Lei de Diretrizes e Bases (LDB), em seu artigo 26 prevê que "Os currículos da educação infantil, do ensino fundamental e do ensino médio devem ter base nacional comum, a ser complementada [...]", por uma parte diversificada, exigida pelas características regionais e locais da sociedade, da cultura, da economia e dos educandos (Brasil, 1996).

Já o Plano Nacional de Educação (PNE) estabelece que "Os Estados, o Distrito Federal e os Municípios deverão elaborar seus correspondentes planos de educação em consonância com as diretrizes, metas e estratégias previstas neste PNE" (Lei 13.005/2014).

A Base Nacional Curricular Comum (BNCC), quando se refere às decisões que caracterizam o currículo em ação, devem considerar a autonomia das redes de ensino e das instituições escolares, como também o contexto e as características dos alunos. Para tanto, prevê que seja necessário "[...] selecionar e aplicar metodologias e estratégias didático-pedagógicas diversificadas, recorrendo a ritmos diferenciados e a conteúdos complementares." Além disso, as ações devem "conceber e pôr em prática situações e procedimentos para motivar e engajar os alunos nas aprendizagens.” (BNCC, 2017, p. 17)

Neste sentido, cabe destacar as reflexões de Cândido e Gentilini (2017), quando ressaltam a importância do Projeto Político Pedagógico (PPP) na caracterização e identidade das escolas, pois ele traz os anseios e pensamentos da comunidade e dos estudantes. Além de se pensar na escola autônoma, mas em sintonia com o sistema. A autonomia é fundamental para a construção curricular, por levar em conta, também, as escolhas da escola, que devem ser pautadas no coletivo. Porém, é uma autonomia relativa. Suanno (2021) ressalta também que cada escola possui peculiaridades e certa autonomia do fazer pedagógico. No entanto, existe leis e planejamentos que precisam ser seguidos por todas.

A partir das considerações do PPP, elabora-se o Plano de Ensino (PE), que guiará o trabalho do professor. O documento trata da organização, planejamento e estruturação no que tange às etapas de ensino. Segundo Queiróz e Palma (2006), a elaboração de um programa é a oportunidade que o docente tem de preparar o que vai oferecer de melhor para o aluno, que consiste na escolha do referencial teórico, na ordem dos conteúdos, identificação das estratégias de ensino, inclusão de resultados de pesquisas apresentados em periódicos.

Neste contexto, o presente artigo tem como objetivo identificar a convergência dos planos de ensino, do $5^{\circ}$ ano do Ensino Fundamental, ao Projeto Político Pedagógico, em relação às metodologias de ensino, de uma escola do estado de Santa Catarina.

\section{Revisão da Literatura}

Nesta seção apresenta-se a revisão da literatura, que sustenta a presente pesquisa, e está assim organizada: a) projeto político pedagógico; b) plano de ensino; c) metodologias de ensino.

\subsection{Projeto Político Pedagógico}

O termo projeto se origina do latim e é identificado na língua portuguesa desde o ano de 1.680, e etimologicamente significa ação de lançar para frente. Pode ser considerado sinônimo de plano, intensão, propósito, delineamento. Quanto aos adjetivos político e pedagógico, as suas etimologias explicitam: político, do grego polit, é um antecedente de polis (cidade), pois envolve uma comunidade; quanto ao pedagógico, no sentido etimológico, se vincula ao sentido de condição da criança. Assim, desde a cultura grega, até a romana, vem se configurando como uma área de conhecimento voltada à estruturação, princípios e diretrizes que tem como finalidade a ação educativa (Veiga \& Araújo, 2016).

No Brasil, a Lei 9.394/1996, que estabelece as diretrizes e bases da educação nacional, em seu artigo 12, inciso I estabelece que: "Os estabelecimentos de ensino, respeitadas as normas comuns e as do seu sistema de ensino, terão a 
incumbência de: elaborar e executar sua proposta pedagógica." (Brasil, 1996). Neste sentido, conforme Cândido e Gentilini (2017, p. 329), “[...] a escola deve organizar, de forma autônoma, seu próprio projeto, isso implica que os profissionais envolvidos devem conhecer muito bem a realidade e, a partir dela, estabelecer as diretrizes de trabalho, seguindo um projeto que seja ao mesmo tempo político e pedagógico."

É oportuno lembrar as palavras de Veiga (2014, p. 1):

O projeto busca um rumo, uma direção. É uma ação intencional, com um sentido explícito, com um compromisso definido coletivamente. Por isso, todo projeto pedagógico da escola é, também, um projeto político por estar infinitamente articulado ao compromisso sociopolítico com os interesses reais e coletivos da população majoritária. É político no sentido de compromisso com a formação do cidadão para um tipo de sociedade.

De acordo a $\mathrm{BNCC}$, as escolhas metodológicas, os currículos e os projetos pedagógicos "devem ser adequados à realidade de cada sistema ou rede de ensino e a cada instituição escolar, considerando o contexto e as características dos seus alunos" (Brasil, 2017, p.30).

Sendo assim, "[...] o Projeto Político-Pedagógico deve ser construído de forma coletiva, envolvendo a comunidade e os representantes de todas as esferas envolvidas com o processo de ensino e aprendizagem." Caracteriza a identidade da escola, dando sentido à instituição e aos grupos e indivíduos que a constituem (Cândido \& Gentilini, 2017, p. 330).

O PPP deve ser um documento vivo em que o diretor, coordenador pedagógico e os professores possam revisá-lo com frequência para as tomadas de decisões, afinal deverá ser reformulado com regularidade, para que as atividades que não estejam alcançando os propósitos satisfatoriamente, possam ser revisados e assim atingir o objetivo pretendido, aperfeiçoando a prática pedagógica. Conforme Lima (2002, p.42): “A construção da escola democrática constitui, assim, um projeto que não é sequer pensável sem a participação democrática de outros setores e o exercício da cidadania crítica de outros atores, não sendo, portanto, obra que se possa ser edificada sem ser em co-construção".

\subsection{Plano de Ensino}

Ao considerar as formas de aprender e ensinar, advém a necessidade de lidar com o conhecimento no sentido de organizar, ordenar, definir procedimentos metodológicos que sejam capazes de nortear alunos e pais nos espaços políticos e sociais. Nessa perspectiva cita-se o artigo 13 da LDB, no que se refere à:

Os docentes incumbir-se-ão de:

I - participar da elaboração da proposta pedagógica do estabelecimento de ensino;

II - elaborar e cumprir plano de trabalho, segundo a proposta pedagógica do estabelecimento de ensino. (Brasil, 1996).

Deste modo, além de participar no processo de elaboração do PPP, os docentes têm a incumbência de elaborar e cumprir o plano de trabalho. Para Leal (2005, p. 1) "O planejamento é um processo que exige organização, sistematização, previsão, decisão e outros aspectos na pretensão de garantir a eficiência e eficácia de uma ação, quer seja em um nível micro, quer seja no nível macro."

Para Libâneo (2013, p.3) "O plano de ensino (ou plano de unidade) é a previsão dos objetivos e tarefas do trabalho docente para o ano ou semestre; é um documento mais elaborado, dividido por unidades sequenciais, no qual aparecem objetivos específicos, conteúdos e desenvolvimento metodológicos.” Já Vasconcellos (2002) utiliza o Plano de Ensino como Plano de Unidade no que tange à organização, à proposta geral da ação do professor em um específico componente curricular ou área de estudo; o plano poderá ocorrer anualmente ou semestralmente. 
Ainda de acordo com Libâneo (2013, p. 245):

O planejamento escolar é uma tarefa docente que inclui tanto a previsão das atividades didáticas em termos da sua organização e coordenação em face dos objetivos propostos, quanto a sua revisão e adequação no decorrer do processo de ensino. O planejamento é um meio para se programar as ações docentes, mas é também um momento de pesquisa e reflexão intimamente ligado à avaliação.

Planejar é prever ações a serem desenvolvidas para se alcançar objetivos determinados. O período inicial é só um primeiro momento de organização, que exigirá novos momentos de reflexão e ajustes. O planejamento é um processo dinâmico, que não se confunde com seu produto escrito. O principal produto do planejamento, é imaterial e consiste na melhoria das condições individuais e de grupo, para o desenvolvimento de trabalho coletivo que exige integração de ações (Russo, 2016).

O planejamento é atividade intrínseca à educação por suas características de evitar o improviso, prever o futuro, nortear adequadamente a execução da ação educativa, especialmente quando garantido a socialização do ato de planejar, que consiste de acompanhamento e avaliação das ações (Padilha, 2001).

Neste sentido, Vasconcellos (2002) menciona que o plano de aula deve ser elaborado, acima de tudo, como uma necessidade do professor e não por exigência formal da direção. Deste modo, sugere que o plano de aula seja estruturado a partir das dimensões: análise da realidade; projeção de finalidades; e, formas de mediação, considerando os elementos apresentados na Tabela 1 .

Tabela 1 - Elementos do Plano de Ensino.

\begin{tabular}{|l|l|}
\hline Elementos & Descrição \\
\hline Assunto & indicação da temática que será trabalhada \\
\hline Necessidade & necessidades percebidas no grupo e que justificam a proposta de ensino \\
\hline Objetivo & $\begin{array}{l}\text { explicitação do objetivo de ensino daquele assunto, relacionado com o sentido do ensino sobre determinado } \\
\text { conteúdo }\end{array}$ \\
\hline Conteúdo & $\begin{array}{l}\text { o nível de detalhamento do conteúdo dependerá do conhecimento do professor sobre assunto: mais detalhado, caso } \\
\text { seja assunto a ser explorado; menos detalhe, em caso de maior conhecimento prévio, necessitando apenas da } \\
\text { síntese, para memória. }\end{array}$ \\
\hline Metodologia & procedimentos de ensino, técnicas, estratégias a serem utilizadas. É o caminho concreto a ser trilhado. \\
\hline Tempo & previsão do tempo a ser empregado com determinado assunto \\
\hline Recursos & indicação dos recursos a serem utilizados, sem desperdiçar a oportunidade de indicação de novos recursos \\
\hline Avaliação & $\begin{array}{l}\text { quais estratégias o professor irá utilizar para acompanhar o processo de desenvolvimento e construção do } \\
\text { conhecimento. A partir dela tem-se elementos para replanejar o trabalho. }\end{array}$ \\
\hline Tarefa & $\begin{array}{l}\text { indicação de tarefas que serão propostas para serem feitas fora da sala de aula. Devem estar relacionadas aos } \\
\text { objetivos propostos. }\end{array}$ \\
\hline Observações & $\begin{array}{l}\text { registro do professor sobre o cotidiano: o que fez, como fez, o que deixou de fazer. Poderá anotar sua reflexão e } \\
\text { avaliação sobre a caminhada. Torna-se instrumento de pesquisa sobre sua prática }\end{array}$ \\
\hline
\end{tabular}

Fonte: Vasconcellos (2002).

Observa-se que a sugestão do autor prevê a evidenciação da justificativa da proposta de ensino e destaca que os recursos não se limitem ao previsto no plano de aula, mas, que se possam indicar novos recursos. Outro aspecto, é o registro das observações, que poderão ser utilizados como instrumento de pesquisa.

\subsection{Metodologias de ensino}

Segundo Nérice citado por Brighenti, Biavatti e Souza (2015), a metodologia do ensino inclui: método e técnicas de ensino, cuja diferenciação não é muito clara. Pode-se dizer que o método se efetiva por meio de técnicas de ensino, que são utilizadas para alcançar os objetivos instituídos. 
Para Veiga (2006, p. 8), “As técnicas de ensino são componentes operacionais dos métodos de ensino que, por sua vez, estão vinculados a um ideário pedagógico [...]” têm caráter instrumental, e são mediações entre professor e aluno, e entre aluno e aluno. Porém, não são suficientes do processo didático.

De acordo com Freiberger e Berbel (2010), a ênfase dada aos conteúdos que precisam ser vencidos no decorrer dos bimestres letivos, a busca por resultados e, em alguns casos, por notas, faz com que o professor seja um transmissor de conteúdos, adotando metodologias que contemplam mais a cópia e as respostas explicativas, do que o estímulo a questionamentos, à elaboração de perguntas pelo aluno e a instrumentação pela pesquisa.

Uma das premissas do ensino socializado refere-se ao estabelecimento do diálogo que engaja professor e alunos num esforço e respeito, procurando compreender, de forma crítica, a realidade social. Assim, estabelece-se espaço para a convivência e o cumprimento do trabalho pedagógico, onde o professor assume o papel pedagógico de forma intencional, sistemática e planejada, provocando questões, reflexões e delineando caminhos em direção a um processo de ensino aprendizagem mais dinâmico (Veiga, 2006). De acordo com Anastesiou (2003, p. 7), “[...] a ação de ensinar está diretamente relacionada à ação de apreender [...]. As orientações pedagógicas não se referem mais a passos a serem seguidos, mas a momentos a serem construídos pelos sujeitos em ação.”

Segundo Vasconcellos (2002), a metodologia é designada como: procedimentos de ensino, técnicas e estratégicas a serem utilizadas para o desenvolvimento de determinado assunto; é o caminho a ser trilhado, e pode indicar, tanto as atividades a serem desenvolvidas pelos professores, quanto pelos alunos. Deve considerar a especificidade do objeto de conhecimento, da disciplina ou de tema abordado numa mesma disciplina, podendo ser mais adequado atividades diferenciadas, como: uso de laboratório, pesquisa teórica, debates, observação direta da realidade, projeção de filmes, entre outras.

Além destas atividades menciona-se, também, o experimento. No entanto, de acordo com estudo realizado por Faria et al. (2020), as aulas práticas com experimentos científicos poderiam ser ampliadas, a partir de parceria entre a escola e instituições de ensino superior, com a possibilidade de fornecer equipamentos ou proporcionar visitas técnicas, pois a principal dificuldade encontrada pelos professores, na aplicação de experimentos em sala de aula, é especificamente os recursos e condições que a escola não oferece. Constatou-se, também, que os alunos têm uma visão de que os experimentos de ciências em sala de aula aumentam a eficácia do aprendizado da disciplina.

\section{Procedimentos Metodológicos}

A pesquisa que fundamenta esse artigo é descritiva e a abordagem do problema é de cunho qualitativo. Quanto aos procedimentos de coleta de dados, é uma pesquisa documental. Para Triviños (2009), a análise documental é um estudo descritivo que fornece ao pesquisador a possibilidade de reunir grande quantidade de informações de vários documentos.

Nesta pesquisa os documentos analisados são os Planos de Ensino das disciplinas de ciências, geografia, história, matemática, língua inglesa, língua portuguesa, artes e educação física, e o Projeto Político Pedagógico de uma escola localizada no estado de Santa Catarina.

Para ter acesso aos documentos, entrou-se em contato com a diretora da escola, a qual enviou os referidos documentos. Para garantir o anonimato, não se evidencia, neste trabalho, o nome da escola. Na Tabela 2 apresenta-se os elementos que compõem os Planos de Ensino que são avaliados. 
Tabela 2 - Elementos dos Planos de Ensino.

\begin{tabular}{|l|l|}
\hline \multicolumn{1}{|c|}{ Elementos do Planos de Ensino } & \multicolumn{1}{|c|}{ Elementos do Planos de Ensino } \\
\hline Sistema de avaliação & Conteúdo \\
\hline Ementa & Referências Básicas \\
\hline Objetivo Geral da Disciplina & Referências Complementares \\
\hline Objetivos Específicos da Disciplinas & Plano de Aula \\
\hline Procedimentos/Processos Metodológicos & \\
\hline
\end{tabular}

Fonte: Autores (2021).

Para o tratamento dos dados, aplica-se a técnica de análise de conteúdo proposta por Bardin (1977), que a define como um conjunto de técnicas de análise das comunicações, e descreve que, dentre outras modalidades, a comunicação pode ocorrer entre um grupo restrito que compreende todas as comunicações escritas, trocadas dentro de um grupo. Neste sentido, o PPP representa uma comunicação entre a escola, os professores, os familiares e os alunos, e o PE é a comunicação entre o professor, os familiares e os alunos.

Para que o tratamento dos dados seja confiável, deve-se levar em conta as unidades de registro que, segundo Bardin (1977), corresponde ao segmento do conteúdo a ser considerado como unidade de base, visando à categorização. Neste estudo, consideram-se como unidade os procedimentos metodológicos descritos nos PEs, para averiguar a convergência com a unidade de registro Metodologia, apresentada no PPP.

\section{Resultados e Discussão}

Nesta seção apresentam-se os resultados da pesquisa. Destaca-se que se utiliza o termo "procedimentos metodológicos" para indicar a metodologia de ensino, pois é o termo que é utilizado nos documentos da escola (PPP e PE). Sendo assim, primeiramente apresentam-se os procedimentos previstos no PPP da escola e, posteriormente, os evidenciados nos PEs de cada componente curricular, para assim averiguar a convergência entre eles.

\subsection{Procedimentos metodológicos previstos no PPP}

Na seção Metodologia do PPP da escola, prevê-se que "A perspectiva sociointeracionista e neuroeducativa propõe uma nova relação entre professor, estudante e conhecimento. Partindo do princípio de que o estudante é construtor do próprio conhecimento, necessita da mediação do professor [...]”.

Ainda estabelece que c o colégio "utiliza procedimentos metodológicos que desafiam e valorizam a atividade mental do estudante na construção e apropriação dos conceitos científicos e na sua aplicação no cotidiano.” Tais procedimentos são elencados a seguir:

A Pesquisa Didática compreende a busca do conhecimento científico através da pesquisa em diversos materiais disponíveis na sala ambiente, na Biblioteca, ou trazidos pelo estudante, seguindo um roteiro dado pelo professor cujo resultado poderá ser apresentado em forma de seminário, produção de texto, debate, relatório, prova, entre outros.

A Resolução de Problemas baseia-se na apresentação de situações abertas e sugestivas que exijam dos estudantes uma atitude ativa ou um esforço para buscar suas próprias respostas, seu próprio conhecimento, promovendo o domínio de procedimentos, assim como a utilização dos conhecimentos disponíveis, para dar resposta a situações variáveis e diferentes.

[...] sequência didática [...] ao organizar a sequência didática, o professor poderá incluir atividades diversas como leitura, pesquisa individual ou coletiva, aula dialogada, produções textuais, aulas práticas, entre outras, pois a sequência de atividades visa trabalhar um conteúdo específico, um tema ou um gênero textual da exploração inicial até a formação de um conceito, uma ideia, uma elaboração prática, uma produção escrita. 
Além desses procedimentos, indica-se no PPP da escola o exercício didático, em que se propõe diferentes tipos de atividades, no contexto da Pedagogia da Integração dos saberes, desenvolvidos por meio de: a) atividades exploratórias, que promovem novas aprendizagens como novos conceitos, regras, formas de entender algo, com base nos conhecimentos prévios dos estudantes; b) atividades de sistematização, que são voltadas para o fundamento dos saberes a serem construídos. Visam sistematizar diferentes saberes que são abordados nas atividades de exploração, como fixar noções e estruturar aquisições.

Por fim, apresentam o projeto de trabalho ou projeto didático, que é uma maneira de organizar as atividades de ensino e de aprendizagem, seguindo determinado eixo, como a definição de um conceito, problema geral ou particular, conjunto de questões inter-relacionadas ou mesmo de uma temática, devendo ser articulado com outras disciplinas na busca das informações sobre um tema. Os objetivos do projeto para alunos de $4^{\circ}$ e $5^{\circ}$ anos são: ordenar, valorizar e conferir às informações abordadas, novos sentidos, significados ou referências (PPP, 2019).

\subsection{Convergência dos PEs ao PPP, em relação aos procedimentos metodológicos}

As Tabelas para análise dos dados são organizadas de acordo com as áreas de conhecimento e Componentes Curriculares (CC) do ensino fundamental dos anos iniciais, previstas na BNCC, conforme Tabela 3.

Tabela 3 - Área de Conhecimento.

\begin{tabular}{|l|l|}
\hline \multicolumn{1}{|c|}{ Área do Conhecimento } & \multicolumn{1}{c|}{ Componentes Curriculares } \\
\hline Linguagens & Língua Portuguesa; Arte; Educação Física; Língua Inglesa \\
\hline Matemática & Matemática \\
\hline Ciências da Natureza & Ciências \\
\hline Ciências Humanas & Geografia; História \\
\hline Ensino Religioso & Ensino Religioso \\
\hline
\end{tabular}

Fonte: BNCC (2017).

Destaca-se que a escola, objeto deste estudo, não oferece o CC de Ensino Religioso, por isso não será apresentado nos resultados.

Para facilitar a análise dos dados, sintetiza-se os procedimentos metodológicos previstos no PPP da escola e insere-se nas Tabelas onde serão apresentadas, também, os procedimentos propostos pelos professores nos PEs, e logo após se verifica o nível de convergência entre eles.

Sendo assim, na Tabela 4 apresentam-se os procedimentos metodológicos da área de Linguagens, que é composta pelos CCs: Língua Portuguesa, Arte, Educação Física e Língua Inglesa. 
Tabela 4 - Procedimentos metodológicos dos CC da área de Linguagens.

\begin{tabular}{|c|c|c|}
\hline \multicolumn{3}{|r|}{ Procedimentos Metodológicos do PPP } \\
\hline \multicolumn{3}{|c|}{ Pesquisa Didática: busca do conhecimento científico através da pesquisa em diversos materiais disponíveis, com roteiro } \\
\hline \multicolumn{3}{|c|}{ Resolução de Problemas: apresentação de situações abertas e sugestivas que exijam dos estudantes uma atitude ativa } \\
\hline \multicolumn{3}{|c|}{ Sequência didática: conjunto de atividades escolares organizadas, de maneira sistemática } \\
\hline \multicolumn{3}{|c|}{ Exercício didático: atividades exploratórias; atividades de sistematização } \\
\hline \multicolumn{3}{|c|}{ Projeto de Trabalho: ordenar, valorizar e conferir às informações abordadas, novos sentidos, significados ou referências } \\
\hline \multicolumn{3}{|r|}{ Plano de Ensino } \\
\hline Área & $\mathbf{C C}$ & Procedimentos Metodológicos \\
\hline \multirow{4}{*}{ 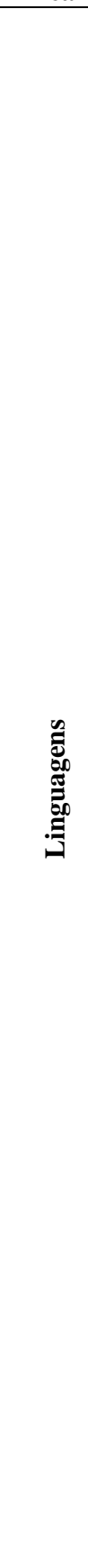 } & 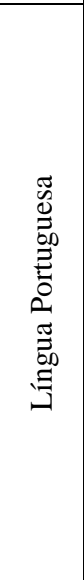 & $\begin{array}{l}\text { Durante o ano serão utilizados os seguintes procedimentos metodológicos: } \\
\text { - Atividades de diagnósticos; } \\
\text { - Apresentação dos conteúdos com aulas expositivas e expositivas dialogada; } \\
\text { - Atividades em grupo; } \\
\text { - Atividades individuais e coletivas dirigidas; } \\
\text { - Atividades individuais e coletivas espontâneas; } \\
\text { - Atividades de reestruturação de textos (linguagem e gramática); } \\
\text { - Atividades de validação/correção; } \\
\text { - Produção de textos individuais e coletivos; } \\
\text { - Tarefas de casa; } \\
\text { - Pesquisas didática; } \\
\text { - Pesquisas e saídas a campo; } \\
\text { - Projetos interdisciplinares; } \\
\text { - Leituras dos diversos gêneros; } \\
\text { - Rotinas de aulas de leitura } \\
\text { - Rotinas de biblioteca }\end{array}$ \\
\hline & 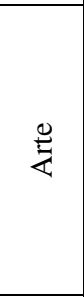 & $\begin{array}{l}\text { A Base Nacional Comum Curricular e Currículo Base de Santa Catarina propõe que a abordagens das linguagens articule } \\
\text { seis dimensões do conhecimento: } \\
\text { - Criação (fazer artístico) } \\
\text { - Crítica (articula ação e pensamento propositivo, envolvendo aspectos estéticos, políticos e históricos) } \\
\text { - Estesia (experiência sensível) } \\
\text { - Expressão (Possibilidades de exteriorização) } \\
\text { - Fruição (Satisfação, sentimento aprazível, estranhamento e à abertura para a sensibilização) } \\
\text { - Reflexão (construir argumentos e ponderações sobre as fruições, as experiências e os processos criativos). }\end{array}$ \\
\hline & 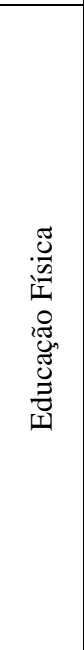 & $\begin{array}{l}\text {-Aulas práticas. } \\
\text {-Obs: Em todos os semestres, as atividades ministradas nas aulas de Educação Física, receberão um tratamento cíclico e } \\
\text { integrado com diferentes graus de aprofundamento observação. } \\
\text { APLICAR AS METODOLOGIAS COM ALGUMAS ABORDAGENS COMO: } \\
\text { 1-DESENVOLVIMENTISTA: Objetivo: Oferecer ao aluno condiçães de desenvolver seu comportamento motor através } \\
\text { da diversidade e complexidade de movimentos. } \\
\text { 2- CONSTRUTIVISTA-INTERACIONISTA: Objetivo: O aluno construir seu conhecimento a partir da interação com o } \\
\text { meio, resolvendo problemas. Construção do conhecimento a partir da interação do sujeito com o mundo. } \\
\text { 3- CRÍTICO-SUPERADORA: Objetivo: Baseado na justiça social. Valoriza a questão da contextualização dos fatos e do } \\
\text { resgate histórico. } \\
\text { 4- CRÍTICO-EMANCIPATÓRIA: Objetivo: promover condições para que a estrutura autoritária dos processos } \\
\text { institucionalizados da sociedade, que forma falsas convicções, falsos interesses e desejos, sejam suspensas e o ensino } \\
\text { encaminhado para uma emancipação, possibilitada pelo uso da linguagem, que tem importante papel no agir } \\
\text { comunicativo. } \\
\text { 5- SAÚDE RENOVADA: Objetivo: informar, mudar atitudes e promover a prática sistemática de exercícios. } \\
\text { 6- PARÂMETROS CURRICULARES NACIONAIS: Objetivos: construção crítica da cidadania, promoção do princípio } \\
\text { da inclusão, com inserção e integração dos alunos à Cultura Corporal do Movimento. Promover os princípios de } \\
\text { igualdade e pluralidade. http://ededfisica.blogspot.com.br/2009/11/abordagens-pedagogicas-na-educacao.html }\end{array}$ \\
\hline & 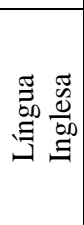 & $\begin{array}{l}\text { As aulas serão ministradas através da abordagem comunicativa defendida pela BNCC. Os objetos de conhecimento serão } \\
\text { ensinados através de aula expositiva usando recursos audiovisuais (lousa digital, multimídia). } \\
\text { As situações de aprendizagem se dão na integração dos eixos de leitura, escrita, oralidade, conhecimentos linguísticos e } \\
\text { dimensão intercultural. } \\
\text { As atividades propostas serão realizadas individualmente e/ou em grupos, trabalhando com os eixos e troca de } \\
\text { experiências entre os alunos }\end{array}$ \\
\hline
\end{tabular}

Fonte: Autores (2021).

Os procedimentos metodológicos propostos pelo professor do CC de Língua Portuguesa convergem com os procedimentos previstos no PPP da escola, como: a) atividades de diagnósticos; aulas expositivas e dialogadas; atividades individuais e coletivas dirigidas e espontâneas; atividades de reestruturação, validação/correção de textos; leitura. Tais atividades convergem com a descrição dos procedimentos metodológicos: sequência didática e exercícios didáticos, previstos 
no PPP; b) a pesquisas didática; rotinas de biblioteca também convergem com o que se prevê no PPP, no item pesquisa didática, que "compreende a busca do conhecimento científico através da pesquisa em diversos materiais disponíveis na sala ambiente, na Biblioteca[...]"; c) projetos interdisciplinares, também previstos no PPP.

Ao se verificar os procedimentos metodológicos do CC de Arte, observa-se que o professor menciona a BNCC e o Currículo Base de Santa Catarina, e apresenta as dimensões do conhecimento, porém, não explicita quais procedimentos metodológicos serão aplicados para desenvolver tais dimensões.

Observa-se que o professor de Educação Física prevê como procedimentos metodológicos as aulas práticas e aplicação de metodologias "com algumas abordagens", como: desenvolvimentista; construtivista-interacionista; críticosuperadora; crítico-emancipatória; saúde renovada; parâmetros curriculares nacionais. Destaca-se que as abordagens previstas no PPP são nas perspectivas sociointeracionista e neuroeducativa.

Quanto ao professor do CC Língua Inglesa, embora mencione abordagem comunicativa, defendida pela BNCC, evidencia poucos procedimentos que convergem com o previsto no PPP da escola, são eles: a) aulas serão ministradas através da abordagem comunicativa e expositiva; eixos de leitura; oralidade, assim como mencionado no procedimento sequência didática; b) atividades individual e/ou em grupos; troca de experiências entre os alunos, tais atividades são previstas no PPP no procedimento exercício didático.

Os procedimentos metodólogos previstos no PE do CC de Língua Portuguesa e, em certa medida, o CC de Língua Inglesa, confirmam o que menciona Vasconcellos (2002) quando sugere procedimentos de ensino, técnicas e estratégicas como o uso de laboratório, pesquisa teórica, debates, observação direta da realidade, projeção de filmes, entre outras.

Na Tabela 5 apresentam-se os procedimentos metodológicos da área de Matemática, que contempla apenas o CC de Matemática.

Tabela 5 - Procedimentos metodológicos da área de Matemática.

\begin{tabular}{|c|c|c|}
\hline & & Procedimentos Metodológicos do PPP \\
\hline Pesquis & dática & usca do conhecimento científico através da pesquisa em diversos materiais disponíveis, com roteiro \\
\hline Resolu & e Prol & mas: apresentação de situações abertas e sugestivas que exijam dos estudantes uma atitude ativa \\
\hline Sequên & idátic & conjunto de atividades escolares organizadas, de maneira sistemática \\
\hline Exercíc & dático & tividades exploratórias; atividades de sistematização \\
\hline Projet & & ordenar, valorizar e conferir às informações abordadas, novos sentidos, significados o \\
\hline & & Plano de Ensino \\
\hline Área & $\mathbf{C C}$ & Procedimentos Metodológicos \\
\hline & 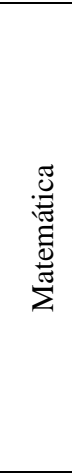 & $\begin{array}{l}\text { O processo de ensinar e aprender constituir-se-á de diversos procedimentos, tais como: 1. Atividades de diagnósticos } \\
\text { 2. Apresentação dos conteúdos com aulas expositivas } \\
\text { 3. Apresentação dos conteúdos com aulas expositivas dialogadas } \\
\text { 4. Atividades em grupo } \\
\text { 5. Atividades individuais espontâneas } \\
\text { 6. Atividades individuais dirigidas } \\
\text { 7. Atividades de validação/ correção } \\
\text { 8. Exercícios de atividades dirigidas } \\
\text { 9. Produção de textos individuais } \\
\text { 10. Tarefa de casa } \\
\text { 11. Seminários de discussões } \\
\text { 12. Pesquisa didática } \\
\text { 13. Jogos didáticos }\end{array}$ \\
\hline
\end{tabular}

Fonte: Autores (2021).

No CC Matemática o professor prevê a aplicação de procedimentos metodológicos que convergem com o previsto no PPP, tais como: a) atividades de diagnósticos; aulas expositivas e dialogadas; atividades individuais e coletivas dirigidas e espontâneas; atividades de reestruturação, validação/correção de textos. Tais atividades convergem com a descrição dos procedimentos metodológicos: sequência didática e exercícios didáticos, previstos no PPP; b) a pesquisas didática; seminário 
de discussão também convergem com o que se prevê no PPP, no item pesquisa didática. Além disso, utiliza como procedimento os jogos didáticos, que não estão explícitos no PPP da escola.

$\mathrm{Na}$ Tabela 6 evidenciam-se os procedimentos metodológicos da área de Ciências, que apresenta apenas o CC também denominado Ciências.

Tabela 6 - Procedimentos metodológicos da área de Ciências.

\begin{tabular}{|c|c|c|}
\hline & & Procedimentos Metodológicos do PPP \\
\hline Pesquis & dática & sca do conhecimento científico através da pesquisa em diversos materiais disponíveis, com roteiro \\
\hline Resoluç & e Prob & nas: apresentação de situações abertas e sugestivas que exijam dos estudantes uma atitude ativa \\
\hline Sequên & idátice & onjunto de atividades escolares organizadas, de maneira sistemática \\
\hline Exercíc & dático & ividades exploratórias; atividades de sistematização \\
\hline Projeto & rabalh & ordenar, valorizar e conferir às informações abordadas, novos sentidos, significados ou referências \\
\hline & & 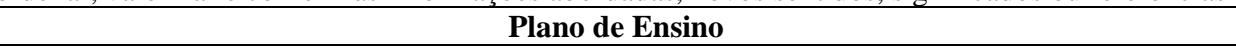 \\
\hline Área & $\mathbf{C C}$ & Procedimentos Metodológicos \\
\hline لِّ & 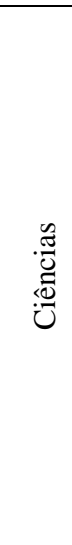 & $\begin{array}{l}\text { 1. Atividades de diagnósticos; } \\
\text { 2. Aulas expositivas; } \\
\text { 3. Aulas expositivas dialogadas; } \\
\text { 4. Atividades em grupo; } \\
\text { 5. Atividades individuais; } \\
\text { 6. Pesquisa didática; } \\
\text { 7. Atividades práticas no laboratório; } \\
\text { 8. Produção de texto coletivo; } \\
\text { 9. Produção de textos individuais; } \\
\text { 10. Tarefa de casa; } \\
\text { 11. Saídas a campo; } \\
\text { 12. Elaboração de relatórios; } \\
\text { 13. Registro de experiências; } \\
\text { 14. Provas individuais; } \\
\text { 15. Exercícios de revisão dos conteúdos. }\end{array}$ \\
\hline
\end{tabular}

Fonte: Autores (2021).

Quanto ao professor do CC de Ciências, apresenta alguns procedimentos metodológicos que convergem com as propostas no PPP, como pesquisa didática, atividades de diagnósticos, aulas expositivas dialogadas, atividades em grupo e individuais, que estão relacionadas à sequência didática, prevista no PPP. Os registros de experiência, saídas de campo e atividades práticas de laboratório, são atividades relacionadas com o procedimento de exercício didático, previsto no PPP.

Na Tabela 7 apresentam-se os procedimentos metodológicos da área de Ciências Humanas, com os CC de História e Geografia. 
Tabela 7 - Procedimentos metodológicos dos UC da área de Ciências Humanas.

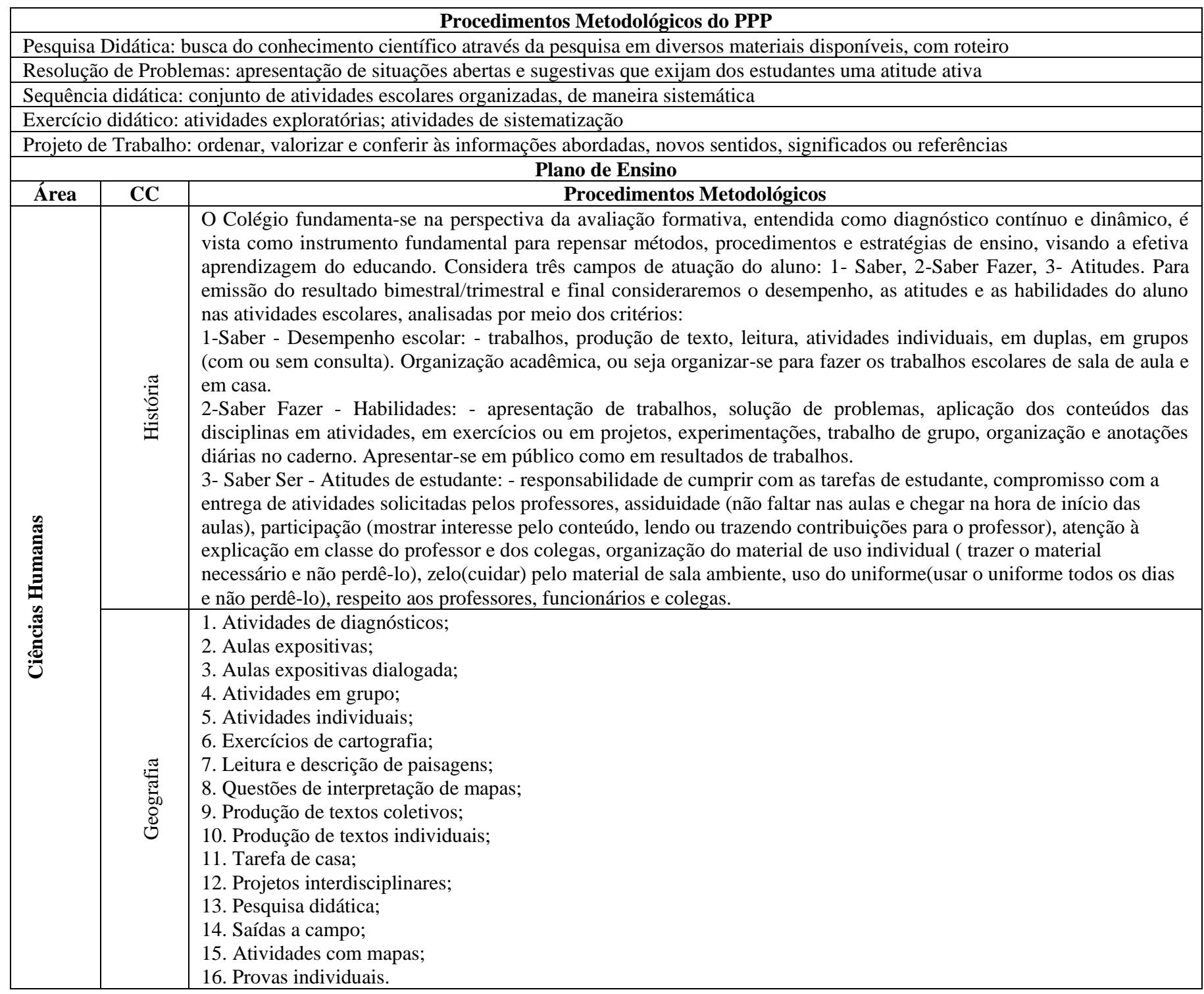

Fonte: Autores (2021).

O professor do CC de História destaca que a escola "fundamenta-se na perspectiva da avaliação formativa, entendida como diagnóstico contínuo e dinâmico, é vista como instrumento fundamental para repensar métodos, procedimentos e estratégias de ensino[...]". Menciona também que se "Considera três campos de atuação do aluno: 1- Saber, 2-Saber Fazer, 3Atitudes”. Que são elementos previstos na seção do PPP denominada: Marco filosófico-pedagógico.

Além disso, o professor não identifica os procedimentos metodológicos, e sim os critérios que identificam o saber, o saber fazer a as atitudes. Embora os critérios remontam a alguns dos procedimentos metodológicos previstos no PPP, como: a) solução de problemas; b) produção de texto, leitura, atividades individuais, em duplas, em grupos, que são evidenciadas no procedimento metodológico denominado sequência didática; c) projetos.

Já o professor de Geografia menciona como procedimentos metodológicos: exercícios de cartografia, leitura e descrição de paisagens, questões de interpretação de mapas, produção de textos coletivos e individuais, que são procedimentos que convergem com o exercício didático, previsto no PPP. Além disso, o professor menciona projetos interdisciplinares e a pesquisa didática, conforme previsto no PPP. 
De forma geral os professores mencionam procedimentos metodológicos previstos no PPP, conforme descrito a seguir: pesquisa didática (evidenciada em quatro PEs); sequência didática (cinco PEs); exercícios didáticos (cinco PEs), no entanto, não mencionam que tipo de exercício, conforme previsto no PPP: atividades exploratórias ou atividades de sistematização. Os projetos de trabalho ou projeto didático são evidenciados em três Planos de Ensino.

Neste aspecto, destaca-se o que menciona Veiga (2006), que técnicas de ensino são componentes operacionais dos métodos de ensino e têm caráter instrumental. São mediações entre professor e aluno, e entre aluno e aluno e, embora sejam condições necessárias e favoráveis do processo didático, não são suficientes. Porém, nem todos os professores deixam suficientemente claro como os procedimentos metodológicos serão abordados, pois não mencionam detalhes de seu desenvolvimento nas aulas, conforme indica Vasconcellos (2002), que a metodologia são procedimentos de ensino, técnicas, estratégias a serem utilizadas. É o caminho concreto a ser trilhado.

\section{Considerações Finais}

O objetivo do presente artigo foi identificar a convergência dos planos de ensino, do $5^{\circ}$ ano do Ensino Fundamental, ao Projeto Político Pedagógico, em relação aos procedimentos de ensino, de uma escola do estado de Santa Catarina.

Quanto ao PPP da escola, observa-se que mencionam a perspectiva sociointeracionista e neuroeducativa, porém não apresentam a base conceitual na qual essas perspectivas são fundamentadas. Por outro lado, no que se refere aos procedimentos metodológicos, evidenciam-se os autores que dão sustentação teórica a maioria dos procedimentos propostos.

Ao se verificar a convergência dos procedimentos metodológicos previstos nos Planos de Ensino com aqueles sugeridos no PPP da escola, observa-se que de maneira geral, os professores mencionam o procedimento propriamente dito ou elementos contidos na sua descrição.

Cabe destacar que a descrição dos procedimentos metodológicos dos componentes curriculares de Educação Física e Arte não condizem com as abordagens propostas pela escola. Assim como o professor de História que apresenta elementos do marco filosófico da escola e a partir daí, menciona alguns procedimentos constantes no PPP. Observa-se também que o professor de Matemática utiliza como procedimento os jogos didáticos, que não estão explícitos no PPP da escola.

Outro aspecto a ser mencionado é que em todos os PEs, o professor apenas elenca os procedimentos, sem esclarecer, de forma mais detalhada como o procedimento metodológico será desenvolvido, embora no PPP, se discorra sobre cada um dos procedimentos.

Esta pesquisa apresenta limitações, pois avaliou-se apenas os PE do $5^{\circ}$ ano e também não permite a generalização. Porém, contribui para a ampliação do conhecimento a respeito dos procedimentos de ensino aplicados no ensino fundamental e sua convergência com o PPP.

Deste modo, sugere-se que novos estudos sejam realizados, no sentido de ampliar a proposta deste artigo e verificar a convergência dos Planos de Ensino ao Projeto Político Pedagógico, no que se refere aos procedimentos de ensino, de outras escolas, tanto públicas, quanto particulares, para assim, poder-se averiguar se há diferença ou similaridades nos resultados.

\section{Referências}

Anastasiou, L. G. C. (2003). Ensinar, aprender, apreender e processos de ensinagem. In L. G. C. Anastasiou \& L. P. Alves (Ed.), Processos de ensinagem na universidade (p.17-44). Editora Univille.

Brasil. (2016). Ministério da Educação. Base Nacional Curricular Comum, http:// basenacionalcomum.mec.gov.br.

Brasil. (1996). Lei de Diretrizes e Bases da Educação Nacional. Lei n. 9.394/96. http://www.planalto.gov.br/ccivil_03/leis/L9394.htm.

Brasil. (2014). Lei n ${ }^{\circ}$ 13.005/2014. Plano Nacional de Educação. http://pne.mec.gov.br/18-planos-subnacionais-de-educacao/543-plano-nacional-de-educacaolei-n-13-005-2014. 
Research, Society and Development, v. 10, n. 14, e565101422207, 2021

Bardin, L. (1977). Análise de conteúdo. Edições 70.

Brighenti, J. Biavatti, V. T. \& Souza, T. R. (2015). Metodologias de ensino-aprendizagem: uma abordagem sob a percepção dos alunos. Revista Gestão Universitária na América Latina-GUAL, 8 (3), 281-304.

Cândido, R. K \& Gentilini, J. A. (2017). Base Curricular Nacional: reflexões sobre autonomia escolar e o Projeto Político-Pedagógico. Revista Brasileira de Política e Administração da Educação-Periódico científico editado pela ANPAE, 33 (2), 323-336.

Faria, M. B., Parente, R. S., Bastos, R. S., de Freitas Silva, W., Ferreira, F. M., de Alencar, D. B. \& Barros, I. N. (2020). A importância do uso de experimentos científicos para o ensino de Ciências no Ensino Fundamental: Um estudo de caso. Research, Society and Development, 9(7), 1-15.

Freiberger, R. M. \& Berbel, N. A. N. (2010). A importância da pesquisa como princípio educativo na atuação pedagógica de professores de educação infantil e ensino fundamental. Cadernos de Educação, (37).

Leal, R. B. (2005). Planejamento de ensino: peculiaridades significativas. Revista Iberoamericana de Educación, 37 (3), 1-6.

Libâneo, J. C. (1991). O planejamento escolar. Didática. Cortez, p. 221-247.

Lima, L. C. (2002). Organização escolar e democracia radical: Paulo Freire e a governança democrática da escola pública. Corte.

Padilha, P. R. (2001). Planejamento dialógico: como construir o projeto político pedagógico da escola. Cortez.

Queiróz, D. A. Palma, M. R. B. (2006). A gestão do currículo do curso superior de Ciências Contábeis. Didática do ensino da contabilidade: aplicável a outros cursos superiores. Saraiva.

Russo, M. H. (2016). Planejamento e burocracia na prática escolar: sentidos que assumem na escola pública. Revista Brasileira de Política e Administração da Educação-Periódico científico editado pela ANPAE, 32 (1), 193-210.

Suanno, J. H. (2021). Educação como prática social com justiça social: um olhar criativo, complexo e transdisciplinar. Revista Polyphonía, 32 (1), 86-99.

Triviños, A. N. S. (2009). Introdução à pesquisa em ciências sociais: a pesquisa qualitativa em educação. Atlas.

Vasconcelos, C. S. (2002). Planejamento: projeto de ensino-aprendizagem e projeto político-pedagógico - elementos metodológicos para elaboração e realização. Liberdat.

Veiga, I. P. A. (2013). Projeto político-pedagógico da escola: uma construção possível. Papirus Editora.

Veiga, I. P. A. (2006). Técnicas de ensino: novos tempos, novas configurações. Papirus Editora.

Veiga, I. P. A. \& Araújo, J. C. S. (2016). O Projeto Político-pedagógico: um guia para a formação humana. In. I. P. A. Veiga. Quem sabe faz a hora de construir o projeto político-pedagógico. Papirus. 